\title{
A QUESTÃO SOCIAL NO BRASIL: UMA ABORDAGEM A PARTIR DA CONTRARREFORMA DO ESTADO BRASILEIRO
}

\author{
Inácio Ferreira Façanha Neto ${ }^{1}$ \\ Josanne Cristina Ribeiro Ferreira Façanha ${ }^{2}$
}

\section{RESUMO}

Trata-se de pesquisa bibliográfica, descritiva e qualitativa, que tem por objetivo abordar a evolução da Questão Social no Brasil, a partir da abordagem da contrarreforma do Estado Brasileiro. Tratada inicialmente como um caso de polícia, a Questão Social era reprimida e renegada pela sociedade e pelo Estado. Em seguida, a partir do Governo Vargas em 1930, passou a ser tratada como caso de política, culminando com a criação dos direitos sociais e de diversas legislações voltadas à classe trabalhadora. Além disso, o tratamento dado à questão social foi sendo moldado a partir da contrarreforma do Estado brasileiro.

Palavras-chave: Caso de polícia. Caso de política. Contrarreforma. Estado Brasileiro. Questão Social.

\section{THE SOCIAL QUESTION IN BRAZIL: AN APPROACH BASED ON THE COUNTER-REFORM OF THE BRAZILIAN STATE}

\begin{abstract}
It is a descriptive and qualitative bibliographical research, whose objective is to approach the evolution of the Social Question in Brazil, based on the counterreform approach of the Brazilian State. Initially treated as a police case, the Social Question was suppressed and denied by society and the State. Then, from the Vargas Government in 1930, it came to be treated as a case of politics, culminating in the creation of social rights and various legislation aimed at the working class. Moreover, the treatment given to the social question was shaped by the counterreformation of the Brazilian State.
\end{abstract}

Keywords: Police case. Case of policy. Counter Reformation. Brazilian State. Social issues.

\section{INTRODUÇÃO}

O século XXI tem sido marcado por profundas alterações no âmbito das políticas sociais, tanto nos países centrais quantos nos periféricos. As grandes transformações econômicas e sociais, especialmente o rearranjo do mercado capitalista, a regionalização dos mercados e a crescente concentração do capital financeiro, vêm ocasionando o aumento da

\footnotetext{
${ }^{1}$ Professor universitário. Mestrando em Administração e Controladoria pela Universidade Federal do Ceará (UFC). Especialista em Gestão Estratégica de Pessoas pelo Uniceuma, em Gestão Empresarial pela Unice e em Segurança Pública, Defesa Civil e Cidadania pela Universidade Estadual do Maranhão (UEMA). Administrador e Tecnológo em Segurança Empresarial e Patrimonial. Email: inacio_facanha@hotmail.com

${ }^{2}$ Professora universitária. Advogada militante. Doutoranda em Políticas Públicas pela Universidade Federal do Maranhão. Doutora em Ciências Jurídicas e Sociais pela Universidad del Museo Social Argentino (UMSA). Mestre em Políticas Públicas pela Universidade Federal do Maranhão. Email: jocrf_2009@hotmail.com
} 
pobreza e da exclusão de vastos contingentes populacionais. Assim, tem-se o escopo das necessidades humanas que são dadas como direito social (iniciativa pública) e quais são relegadas ao mercado (iniciativa privada) (ESPING-ANDERSEN).

Marx (2013), ao analisar o desenvolvimento capitalista, identifica como a origem da questão social as condições materiais e as relações sociais que (re) produzem a desigualdade entre as classes, condicionada pelo acúmulo de capital. Assim, a proteção social emerge enquanto direito social a partir da organização da classe trabalhadora, atingida pelos problemas sociais advindos da desigualdade social, construída ao longo do processo da industrialização e da consequente acumulação capitalista. A partir da segunda metade do século XX, teve início uma nova era mundial. Chegava ao fim um período de grandes tensões, marcado, principalmente, por duas grandes guerras, que transformaram a dinâmica global, tanto do ponto de vista socioeconômico, quando da ótica política e cultural.

Diante desse cenário, o chamado Estado de Bem-Estar Social foi a saída encontrada pelos países para sustentar as reformas demandadas pela população. Proteção social constituise em medidas que atendam aos indivíduos diante dos problemas e riscos sociais. Segundo Yasbek (2001), decorre das vicissitudes da vida natural ou social, tais como velhice, doença, infortúnio e privações, além da distribuição e redistribuição de bens materiais e culturais.

A primeira expressão da questão social advém do pauperismo decorrente dos impactos da primeira onda industrializante, passando a ganhar destaque particularmente, a partir da última metade do século XIX, período em que o capitalismo experimenta profundas modificações no seu ordenamento e na sua dinâmica econômica, com incidência necessária na estrutura social e nas instâncias políticas das sociedades (NETTO, 2001).

Dessa forma, compreendendo esta perspectiva que se pretende ao longo desse trabalho discutir o que se entende por questão social e quais são as suas tendências na contemporaneidade, a partir do seu delineamento pela contrarreforma do Estado Brasileiro, o que ocorreu com a inserção dos direitos sociais na Constituição Federal de 1988.

2 ORIGEM DA QUESTÃO E DA SEGURIDADE SOCIAL NO BRASIL: análise das conjunturas social, política e histórica

Durante a Primeira Guerra Mundial a indústria brasileira registrou alto índice de expansão, resultado do declínio do comércio internacional e da consequente necessidade de substituição das importações. Em razão do crescimento das atividades industriais, o 
contingente de trabalhadores organizados aumentou de modo a fortalecer o movimento operário. Nos anos de 1917 a 1920, inúmeras greves foram deflagradas nos principais centros urbanos do país, motivo pelo qual o debate acerca da chamada "questão social" e as medidas necessárias para seu enfrentamento conquistou espaço no cenário político nacional (BRANDAO, 2014).

No plano internacional, a discussão sobre a questão social também ganhou enfoque, tendo o Brasil participado da Conferência do Trabalho de Washington em 1919. Nesse mesmo ano, ocorreram as eleições presidenciais no Brasil, sendo esse tema explorado pelo candidato de oposição Rui Barbosa. Apesar de não ter contado com o apoio de uma máquina eleitoral, Rui Barbosa conseguiu sair vitorioso no Rio de Janeiro, então capital da República, com aproximadamente um terço dos votos (BRANDAO, 2014).

O objetivo central da classe operária era melhorar as condições de vida, de trabalho e salário. Já o empresariado considerava a possibilidade de fazer algumas concessões ao operariado para garantir o processo de produção e de acumulação de capital e, simultaneamente, fazer frente às críticas anti-industrialistas que acusavam o setor de ser o causador do aumento do custo de vida além de estimulador de graves problemas sociais com sua intransigência.

De acordo com Castel (1998), o "social” está presente desde o século XVI, por meio das intervenções públicas que iam desde a assistência aos indigentes até a regulação estatal da organização do trabalho. Entretanto, a assistência pública era resumida apenas a situações de indigência, na qual estruturadas da assistência confessional não haviam sido quebradas.

Para Netto (1992), o desenvolvimento do capitalismo imperialista visava à urgência de viabilizar um objetivo primário: o acréscimo dos lucros capitalistas através de controles de mercado. Juntamente a esse cenário, outros elementos típicos da monopolização também fazem seu ingresso: a supercapitalização que se caracteriza pela dificuldade de valorização do montante de capital acumulado, e o parasitismo da vida social da burguesia. É nesse contexto, que o Estado passa a atuar com o cioso guardião das condições externas da produção capitalista, direcionando-se para garantir os superlucros dos monopólios.

No Brasil, podemos afirmar que a "questão social" consistiu em um processo tardio, em razão do modelo implantado pelo sistema colonial, baseado no trabalho escravo, na monocultura agrícola e no latifúndio exportador, todos subordinados aos grandes expoentes da economia mundial, fato que marcou em absoluto a vida econômica, política, social e 
cultural de nosso país. Na verdade, a Questão Social era reprimida pela sociedade, pelo Estado, por ser considerada com um caso de polícia.

Antes de 1930, a questão social não aparecia no discurso dominante, sendo fato excepcional e episódico, uma vez que não possuía condições de se impor ao pensamento dominante (CERQUEIRA FILHO, 1982).

Iamamoto (2001) aponta que a questão social é indissociável da sociabilidade capitalista e que na sociedade burguesa a gênese da questão social deriva do caráter coletivo da produção contraposto à apropriação privada da própria atividade humana, esta condensaria então o conjunto das desigualdades e lutas sociais, produzidas e reproduzidas no movimento contraditório das relações sociais, tendo alcançado a plenitude de suas expressões e matizes em tempo de capital fetiche.

Para autora, a questão social expressa desigualdades econômicas, políticas e culturais das classes sociais, decorrentes das disparidades nas relações de gênero, características étnicoraciais e formações regionais, colocando em causa amplos segmentos da sociedade civil no acesso aos bens da civilização. Destaca, ainda, que foram as lutas sociais que romperam o domínio privado nas relações entre capital e trabalho, extrapolando a questão social para esfera pública exigindo a interferência do Estado para o reconhecimento e a legalização de direitos e deveres dos sujeitos sociais envolvidos. Por fim, aponta que na perspectiva por ela assumida, a questão social não se identifica com a noção de exclusão social, hoje generalizada, dotada de grande consenso nos meios acadêmicos e políticos.

Dessa forma, a pobreza seria uma face do rejeite de mão de obra barata, que faz parte da expansão capitalista. Assim, segundo a autora, as sequelas da "questão social" expressas na pobreza, na exclusão e na subalternidade de grande parte dos brasileiros tornam-se alvo de ações solidárias e de filantropia revisitada, fazendo parte deste quadro à crônica crise das políticas sociais, seu reordenamento e sua subordinação às políticas de estabilização da economia, com suas restrições aos gastos públicos e sua perspectiva privatizadora.

Yazbek (2001) comenta Telles (2013) quando esta aponta que no momento atual, despolitiza-se o reconhecimento da questão brasileira como expressão de relações de classe e neste sentido, desqualifica-a como questão pública, questão política, questão nacional, numa sociedade privatizada que desloca a pobreza para o "lugar de não política, onde é franqueada como um dado a ser administrado teoricamente ou gerado pelas práticas de filantropia”.

Yazbek (2001) entende que a reprodução ampliada da questão social é reprodução das contradições sociais, que não há rupturas no cotidiano sem resistência, sem enfrentamentos e 
que se a intervenção profissional do assistente social circunscreve um terreno de disputa, é ai que está o desafio de sair da lentidão, de construir, reinventar mediações capazes de articular a vida social das classes subalternas com o mundo público dos direitos e cidadania.

A Questão Social aparece como caso concreto no Brasil no quadro do processo de industrialização e implantação do modo de produção capitalista e o surgimento da classe operária.

Somente na década de 30, período do governo Vargas, o Estado passa a considerar a Questão Social como um problema político (“caso de política”), porém diversos aspectos são reprimidos pela polícia. Nesse momento, foi criado um sistema de proteção social básico, com criação da legislação trabalhista, Institutos de Aposentadorias e Pensões e a Consolidação das Leis Trabalhistas, havendo uma "introdução" do chamado Estado de Bem-Estar Social, com fundamento no modelo da Europa Ocidental, em resposta à Questão Social.

Desse modo, até a inauguração da Era Vargas, o Direito Social Brasileiro só abrangia poucos aspectos da questão trabalhista e menos ainda da questão previdenciária. Seja como for, a implantação de uma legislação social como um todo após a Revolução de 1930 tem suas raízes nessas iniciativas pioneiras e na luta dos trabalhadores desse período.

Castel (1998) analisa as transformações históricas da sociedade capitalista, assinala que a "questão social" é uma aporia fundamental sobre a qual uma sociedade experimenta o enigma de sua coesão e tenta conjurar o risco de sua fratura, ou seja, é um desafio que interroga, põe em questão a capacidade de uma sociedade para existir como um conjunto ligado por relações de interdependência.

Destarte, para Castel (1998), a questão social pode ser caracterizada por uma inquietação quanto à capacidade de manter a coesão de uma sociedade. A ameaça de ruptura é apresentada por grupos cuja existência abala a coesão do conjunto, sendo que a gênese desta questão foi suscitada pelo distanciamento do crescimento econômico e o aumento da pobreza e pela ordem jurídico-política que reconhecia os direitos sociais dos cidadãos e uma ordem econômica que os negava.

Portanto, a diferença da questão social na fase do capitalismo industrial seria o surgimento de novos atores e conflitos. Com a crise da década de 1970 e o abalo da sociedade salarial, as principais manifestações dessa nova questão social, reflexo do desemprego em massa e da precarização do trabalho, é o reaparecimento de trabalhadores sem trabalho, os inúteis para o mundo ou supranumerários, pessoas que não tem lugar na sociedade porque não são integradas. 
Desse modo, Castel (1998) conclui que a profunda metamorfose da questão social é que enquanto anteriormente a necessidade era saber como um ator social subordinado e dependente poderia tornar-se um sujeito social pleno, hoje a questão é amenizar a presença destas populações postas à margem, torná-las discretas a ponto de apagá-las. Corroborando o pensamento de Castel (1998), Rosavallon (1998) ressalta que as transformações contemporâneas decorrentes da crise da década de 1970, fez surgir uma nova questão social, visto que em suas análises dos sistemas seguradores, os benefícios do crescimento econômico e das conquistas das lutas sociais modificaram a vida dos trabalhadores e o Estadoprovidência quase conseguiu vencer a antiga insegurança social e vencer o medo do futuro.

Logo, a nova questão social se coloca a partir de novos fenômenos de exclusão social decorrentes da crise da década de 1970, o que segundo Rosavallon (1998) apresenta três dimensões: uma financeira, uma vez que os gastos são maiores que o ingresso de recursos; uma ideológica, devido à falta de eficácia do Estado empregador para enfrentar as questões sociais; e uma filosófica, pela desintegração dos princípios que organizam a solidariedade e a concepção tradicional de direitos sociais. Assim, as políticas sociais consideram os indivíduos em sua singularidade, tendo como meta dar a cada um os meios para que modifique a sua vida e, para tanto, é necessário, nesses novos tempos, a proposição de uma nova cultura política.

A singularidade do capitalismo tardio brasileiro, na sua condição periférica, aliada à reestruturação econômica a estrutura 'tradicional', comprometeu as frágeis coberturas sociais públicas, ou seja, em virtude da discussão tardia da questão social no Brasil somada ao processo de crise na economia fragilizou ainda mais as iniciativas governamentais voltadas ao social. Apenas com a promulgação da Constituição de 1988, expressão da mobilização dos interesses democráticos e populares, é que ocorreu o processo de institucionalização dos direitos sociais, colocados agora na contracorrente da ofensiva neoliberal.

A seguridade social "compreende um conjunto integrado de ações de iniciativa dos Poderes Públicos e da sociedade, destinadas a assegurar os direitos relativos à saúde, à previdência e à assistência social", conforme preceituado pelo caput do art. 194 da Constituição Federal de 1988.

O sistema securitário social consolida a proteção do indivíduo contra eventuais riscos que possam ocorrer, seja por meio da saúde, da assistência social e da previdência social.

Não obstante, para a efetivação deste sistema, é indispensável a parceria entre Estado e sociedade, na composição da Seguridade Social, a ser prestada de forma igualitária a todos que dela necessitarem. 
Diante da noção de Seguridade, a primeira manifestação pré-jurídica do fenômeno securitário, ocorreu com o chamado assistencialismo ou caridade, norteado pela ideia de assistência pública difundida pela Lei dos Pobres de 1601, da Rainha Elizabeth da Inglaterra.

A segunda manifestação pré-jurídica foi o chamado mutualismo, criado pelos próprios trabalhadores, que se agrupavam nas sociedades de socorros mútuos. A partir desses movimentos sociais, o Poder Público decide substituir os particulares e assumir a responsabilidade pela proteção social.

Em 1883, com a promulgação da Lei do Seguro Doença na Alemanha, durante o governo de Otto Von Bismarck, o Estado passou a se responsabilizar efetivamente pela proteção dos trabalhadores quando vítimas dos riscos sociais. Nesse momento, a noção de seguro do direito privado é transportada para o direito público, o chamado seguro social.

Boschetti (2006, p. 02) fala a respeito do nascimento da Seguridade Social:

As primeiras iniciativas de benefícios previdenciários que vieram a constituir
a seguridade social no século XX nasceram na Alemanha, no final do século
XIX, mais precisamente em 1883 , durante o governo do chanceler Otto Von
Bismarck, em resposta às greves e pressões dos trabalhadores. O chamado
modelo bismarckiano é considerado como um sistema de seguros sociais,
porque suas características assemelham-se às de seguros privados: no que se
refere aos direitos, os benefícios cobrem principalmente (e às vezes
exclusivamente) os trabalhadores, o acesso é condicionado a uma
contribuição direta anterior e o montante das prestações é proporcional à
contribuição efetuada; quanto ao financiamento, os recursos são
provenientes, fundamentalmente, da contribuição direta de empregados e
empregadores, baseada na folha de salários; em relação à gestão,
teoricamente (e originalmente), cada benefício é organizado em Caixas, que
são geridas pelo Estado, com participação dos contribuintes, ou seja,
empregadores e empregados. Esse modelo orientou e ainda sustenta muitos
benefícios da seguridade social, sobretudo, os benefícios previdenciários.

A primeira Constituição a discutir o seguro social foi a do México, de 1917. Em seguida, a Constituição de Weimar, de 1919, trouxe vários dispositivos referentes à previdência social. A partir do modelo de Bismarck, a técnica protetiva foi difundida pelo mundo, e, no período entre as duas grandes Guerras, essa proteção foi estendida, atingindo um número cada vez maior de pessoas (MARTINEZ, 1998).

Em 1935, nos Estados Unidos, surgiu o chamado Social Security Act, que consistiu na primeira manifestação à seguridade social, demonstrando a preocupação com os excluídos dos regimes previdenciários, defendendo a proteção de toda a população. Apesar da nomenclatura, este ato não representava a criação da Seguridade Social, mas da Previdência 
Social nos moldes atuais, isto é, um modo evoluído de seguro social, que atende as demandas sociais da classe trabalhadora de forma mais ampla.

Anos mais tarde, em 1942, período da Segunda Guerra Mundial, é elaborado na Inglaterra o Plano Beveridge, uma crítica ao sistema de Otto Von Bismarck e que propõe a instituição do Welfare State. Por meio desse sistema, os direitos assumem caráter universal, sendo direcionados a todos os cidadãos, de modo incondicional ou que estejam submetidos a condições de recursos, de modo a garantir o mínimo a todos em situação de necessidade. $\mathrm{O}$ financiamento é advindo de impostos e a gestão é feita pelo Estado, tendo como princípios fundamentais a unificação institucional e a uniformização dos benefícios (BOSCHETTI, 2006).

A evolução da proteção social no Brasil seguiu o mesmo caminho do modelo internacional, qual seja a origem privada e voluntária, com a formação dos primeiros planos mutualistas e a intervenção cada vez mais presente por parte do Estado.

No Brasil, a Constituição de 1824 foi a que primeiro mencionou a assistência a população carente, assegurando-lhes os chamados socorros públicos, anteriormente qualificados pela Declaração dos Direitos do Homem e do Cidadão de 1973, em seu art. 23, como "dívida sagrada".

Entre os anos de 1835 e 1890, surgiram no Brasil algumas legislações que se preocupação com os temas relativos a acidente de trabalho e aposentadoria, como o Montepio Geral dos Servidores do Estado (1835), o Código Comercial (1850) abordando em seu art. 79 os acidentes de trabalho, Regulamento 737 (1850) sobre acidente do trabalho e o Decreto 221 (1890), que tratava da aposentadoria dos trabalhadores da Estrada de Ferro Central do Brasil, a qual, anos depois, foi estendida a todos os ferroviários do país (Decreto 405).

A Constituição Federal de 1891 também assegurou socorros públicos, explicitando as calamidades, dispondo inclusive em seu art. 75 que "a aposentadoria só poderá ser dada aos funcionários públicos em caso de invalidez a serviço da Nação, e sem contribuição". Em 1919, a Lei 3.724, mais conhecida como Lei de Acidente do Trabalho, abordou de maneira mais complexa o tema.

Em 1923, foi promulgado o Decreto Legislativo 4.682, mais conhecido como Lei Eloy Chaves, em homenagem ao seu proponente, que instituiu no Brasil a Previdência Social, com a criação de Caixas de Aposentadoria e Pensões para os ferroviários, em nível nacional. Segundo Ibrahim (2006, p. 30), a Lei Eloy Chaves constitui um marco histórico da Previdência em razão de seu caráter ideológico. 
Os anos posteriores à publicação desta lei foram marcados pelo surgimento de várias Caixas de Aposentadorias e Pensões (CAPS), tanto que em 1937, estas perfaziam aproximadamente o total de cento e oitenta e três. Inicialmente, o vínculo dos filiados advinha das empresas. A partir do fortalecimento dos sindicatos e da classe urbana, bem como do interesse do Estado em criar um sistema de seguridade social, a vinculação passou a ser feita por categoria profissional.

Em 1940, o governo de Vargas criou o Instituto de Serviços Sociais do Brasil, com o objetivo de integrar as instituições previdenciárias existentes, e, em 1960, o Congresso Nacional aprovou Lei Orgânica da Previdência Social, unificando os diversos institutos estendendo a cobertura previdenciária para os empregadores e autônomos.

Todavia, a concretização desta unificação somente veio a ocorrer em 1966 com a criação do Instituto Nacional de Previdência Social (INPS). Em 1963, foi criado o Fundo de Assistência ao Trabalhador Rural (FUNRURAL), tendo por escopo estabelecer direitos e deveres dos empregados e dos produtores rurais.

Na década de 70, a cobertura previdenciária aos trabalhadores foi estendida a cidadãos antes não contemplados pelo sistema, dentre os quais trabalhadores rurais e empregadas domésticas. Além disso, foram incluídas outras questões não abrangidas pela legislação, como os acidentes de trabalho, por exemplo.

Inicialmente, a Previdência Social brasileira se dividia em duas pastas: a pasta do Direito do Trabalho e a da Previdência Social. Majoritariamente, predominava a pasta trabalhista, vez que, nessa época, não havia muitos aposentados, sendo a preocupação reduzida com relação a Previdência Social. Em 1974, em virtude do envelhecimento gradativo da população, criou-se o Ministério de Previdência e Assistência Social, dividindo o INPS em três órgãos: o INPS, que era responsável pelo pagamento dos benefícios previdenciários e assistências; o Instituto de Administração da Previdência e Assistência Social (IAPAS), que administrava e recolhia os recursos do INPS e o Instituto Nacional de Assistência Médica da Previdência Social (INAMPS), que era o responsável pelo sistema de saúde (BOSCHETTI, 2006).

Nos anos 90, foram feitas algumas reformas e fusões, passando o INSS a ser o órgão regulador da Previdência Social. Giambiagi e Além (2003, p. 265) consideram que a consolidação do seguro social, levou a população brasileira a perceber a Previdência Social como um seguro que se transformou em um fator de estabilidade social do país, esta preocupação em garantir uma renda para a população, inclusive para os funcionários públicos, 
e as mudanças que não estão sendo feitas em função do regime de repartição tem causado grandes déficits nas contas do governo.

Mota (2008), por sua vez, assevera que as políticas protetivas como a saúde, a previdência e a assistência social são decorrentes das lutas do trabalho, haja vista responderem pelo atendimento das necessidades baseadas em princípios e valores socializados pelos trabalhadores e reconhecidos pelo Estado e pelos empregadores. Segundo a pesquisadora, não importa quais sejam os objetos específicos de intervenção, saúde, previdência ou assistência social, o objetivo da seguridade dependerá do nível da socialização da política adquirido pelas classes trabalhadoras, bem como das estratégias do capital na incorporação das necessidades trabalhistas.

A Seguridade Social tem como propósito fundamental proporcionar aos indivíduos e às famílias a tranquilidade de saber que o nível e a qualidade de suas vidas não serão significativamente diminuídos, até onde for possível evitá-lo, por nenhuma circunstância econômica ou social. A Seguridade Social não se preocupa em garantir o padrão de vida do indivíduo, mas apenas assegurar-lhes condições mínimas para uma sobrevivência digna.

Sendo assim considerada, a Constituição Federal de 1988 introduziu a designação da Seguridade Social para integrar o conjunto de ações na área da saúde, previdência social e assistência social, estabelecendo princípios, diretrizes gerais e fontes de financiamento.

Dessa forma, a Constituição de 1988 inseriu grandes mudanças na Previdência Social brasileira, em especial no que diz respeito ao funcionalismo público, causando problemas financeiros e econômicos para o governo.

Najberg e Ikeda (1999) comentam o cenário atual da Previdência brasileira:

A Previdência brasileira administra hoje um dos maiores programas de renda mínima do mundo, na exata proporção em que paga benefícios de um salário mínimo por mês a 7,9 milhões de brasileiros que não contribuíram para a previdência social.

Do mesmo modo, o aumento dos gastos do Governo ocasionou uma crise no sistema de saúde nos anos 90, pois até então os gastos da saúde eram financiados pela Previdência Social. A partir da Constituição de 1988, este quadro foi alterado, uma vez que "a previdência social não separa claramente o seguro da assistência” (REZENDE, 2001).

Em 24 de julho de 1991, entraram em vigor as leis fundamentais da Seguridade Social: a Lei $n^{\circ}$. 8.212, dispondo acerca do Plano de Custeio e Organização da Seguridade Social, e a 
Lei $n^{\circ}$. 8.213, tratando do Plano de Benefícios da Previdência Social, revogando totalmente a LOPS.

A LOPS, desde a promulgação da Constituição Federal de 1988 até a publicação dos diplomas citados anteriormente, continuou sendo aplicada em face da inexistência de outra legislação acerca do tema. Este período de aplicação da LOPS, sem que a mesma tenha sido totalmente recepcionada pela nova Carta Magna da República ficou conhecido como "buraco negro", sendo os benefícios concedidos nessa época objeto de revisão, com adoção de novo cálculo da renda mensal, de modo a se adequar às leis novas.

Dentre os princípios estabelecidos pela Constituição Federal de 1988 no que pertine a Seguridade Social, podemos elencar o primado do trabalho e o do ideário do bem-estar e da justiça sociais.

O princípio do primado do trabalho, previsto no art. 193 da Carta Magna, coloca o trabalho como base primordial da ordem social, ou seja, o sistema de seguridade social, tendo seu objetivo interligado ao da ordem social, estará pautado em ações que estabeleçam como prioridade o trabalho. O primado do trabalho é o caminho para que sejam alcançados o bemestar e a justiça sociais.

Com relação ao segundo princípio, a incorporação, pela primeira vez, do conceito ligado à proteção social como o de seguridade social no texto constitucional respondeu às expectativas da sociedade organizada de ampliação dos direitos sociais associados à cidadania, traduzindo a sensibilidade do constituinte diante da situação preexistente.

O Bem-Estar e a justiça sociais representam valores supremos da sociedade, merecendo total prioridade, que surge por meio da proteção ao trabalho.

Para que seja alcançado o bem-estar social a Constituição Federal traz elencados no art. $6^{\circ}$ os direitos sociais: direito à educação, à saúde, ao trabalho, à moradia, ao lazer, à segurança, à previdência social, à proteção à maternidade e à infância, bem como à assistência aos desamparados.

Apesar de ter sido inspirada nos moldes estabelecidos pelo Estado de Bem Estar dos países desenvolvidos, o mercado de trabalho excludente, o nível de pobreza de grande parte da população e a desigualdade na distribuição de renda indicam que o sistema de seguridade social adotado pelo Brasil não garante acesso universal aos benefícios sociais.

Portanto, no Brasil, o seguro social é uma das bases de sustentação da Seguridade Social, cujo objetivo principal é garantir proteção ao trabalhador e a sua família. Entretanto, essa proteção não é absoluta, limitando-se a garantir direitos somente ao trabalhador que 
esteja inserido no mercado de trabalho ou que contribui mensalmente como autônomo ou segurado especial à Seguridade Social.

\section{A PREVIDÊNCIA SOCIAL BRASILEIRA: da origem aos dias atuais}

A Constituição Federal Brasileira, em seu art. 201, estabelece que a Previdência Social será organizada sob a forma de regime geral, de caráter contributivo e de filiação obrigatória. Neste regime, deverão ser observados critérios que preservem o equilíbrio financeiro e atuarial, atendendo a cobertura dos riscos sociais: doença, invalidez, morte, idade avançada, proteção a maternidade, em especial à gestante, e ao trabalhador em situação de desemprego involuntário, conferindo salário-família e auxílio-reclusão para os dependentes dos segurados de baixa renda, bem como a pensão por morte do segurado, homem ou mulher, ao cônjuge ou companheiro e dependentes.

A Lei $n^{\circ}$. 8.213/1991 também dispõe acerca da Previdência Social em todos os aspectos, inclusive estabelecendo os benefícios que serão devidos aos titulares dos direitos previdenciários.

$\mathrm{Na}$ verdade, a Previdência Social é um seguro sui generis, uma vez que é de filiação obrigatória para os regimes básicos, além de ser contributivo e de organização estatal, auxiliando seus beneficiários contra os chamados riscos sociais (IBRAHIM, 2007).

A previdência social é a técnica protetiva mais evoluída que os antigos seguros sociais, em razão da maior extensão da proteção, bem como a flexibilização entre contribuição e benefícios. A solidariedade é mais presente nos sistemas atuais e a seguridade social, como última etapa ainda a ser plenamente alcançada, abrangendo a previdência social, buscando a proteção máxima, a ser implementada de acordo com as possibilidades orçamentárias (TAVARES, 2000).

Restritivamente, os riscos sociais cobertos pelos regimes protetivos são as adversidades da vida a que qualquer indivíduo está submetido, como, por exemplo, um risco de doença ou acidente, ou outros eventos previsíveis como idade avançada, ou seja, fatores que acarretam a impossibilidade do segurado em prover sua mantença.

Entretanto, o conceito de risco social não é tão limitado, abrangendo outras situações avessas à ideia de infortúnio, como é o caso da maternidade. Por esse motivo, a denominação "riscos sociais" é criticada por alguns estudiosos, que sugerem a adoção do termo “necessidade social” (ASSIS, 2009). Igualmente, Durand (1991, p. 55) entende que o 
qualitativo de risco pode ser utilizado para eventos afortunados, devendo o vocábulo "risco social" ser interpretado como todo evento coberto pelo sistema protetivo, com a intenção de oferecer ao segurado algum rendimento substituidor de sua remuneração, como forma de indenizar sequelas sofridas (auxílio doença, auxilia acidente, aposentadoria por invalidez) ou em virtude de encargos familiares (salário família, salário maternidade).

Além dos princípios universais da Seguridade Social, a Previdência possui princípios específicos, elencados no art. 194 da Constituição, que norteiam a sua efetividade, bem como a concessão de benefícios ou prestação de serviço social e/ou reabilitação profissional aos segurados e dependentes. São eles: universalidade da cobertura e do atendimento, uniformidade e equivalência dos benefícios e serviços às populações urbanas e rurais, seletividade e distributividade na prestação dos benefícios e serviços, irredutibilidade do valor dos benefícios, equidade na participação no custeio, diversidade da base de financiamento e, caráter democrático e descentralizado da administração, mediante gestão quadripartite, com participação dos trabalhadores, dos empregadores, dos aposentados e do governo nos órgãos colegiados.

O princípio da universalidade de cobertura e de atendimento significa que qualquer pessoa pode participar da proteção social patrocinada pelo Estado. Essa universalidade é inerente ao sistema de seguridade social, visando o atendimento de todas as demandas sociais na área securitária.

A uniformidade e equivalência de prestações urbana e rural indica que as prestações securitárias devem ser idênticas para trabalhadores rurais ou urbanos, não sendo lícita a criação de benefícios diferenciados.

A seletividade fixa o rol de prestações que serão garantidas ao beneficiário do sistema, enquanto a distributividade direciona a atuação do sistema protetivo para as pessoas com maior necessidade, definindo o grau de proteção (BALERA, 2004).

A irredutibilidade no valor dos benefícios representa que os benefícios não poderão ser reduzidos, devendo ser preservado o seu valor real. A irredutibilidade busca não apenas a manutenção do poder aquisitivo, como também o progresso econômico.

A equidade na forma de participação no custeio é decorrente do princípio da igualdade, fundamentando-se na capacidade econômica dos contribuintes. Desse modo, quanto maior capacidade econômica revelar o contribuinte, maior deverá ser a quota a ser revertida ao fundo social para financiar as prestações. 
A diversidade da base de financiamento possui duas dimensões: a objetiva, que corresponde aos fatos a serem objeto de contribuições, e a subjetiva, relacionada a pessoas naturais ou jurídicas que deverão contribuir.

Finalmente, o caráter democrático e descentralizado da administração mediante gestão quadripartite, com participação dos trabalhadores, empregadores, aposentados e governo nos órgãos colegiados, tem por escopo resguardar a administração do sistema com a qualidade da segurança e moralidade.

Segundo Ciquine apud Canuto e Fernandes (2000), “o financiamento dos sistemas previdenciários pode ser realizado através de dois regimes: o de repartição e o de capitalização".

Rezende (2001, p. 163) lembra que "o modelo de previdência no Brasil é caracterizado por um regime de repartição", funcionando como um orçamento anual em que os trabalhadores e empregadores (com suas contribuições) financiam as aposentadorias dos trabalhadores inativos. Os trabalhadores, que estão em atividade, futuramente, serão aposentados, sendo estas financiadas pelos trabalhadores atuais. Apesar de ser um sistema contributivo, a Previdência não perde o caráter solidário, já que a contribuição objetiva a geração de renda a pessoa idosa ou deficiente e, que, portanto, não dispõe de capacidade laborativa.

Para o bom funcionamento desse sistema, é necessária a implementação de alguma forma de controle. Isso porque as mudanças demográficas do país somadas as alterações no mercado de trabalho são fatores determinantes para que este regime alcance resultados positivos. Rezende (2001, p. 165) esclarece que "o problema do regime de repartição é que ele não guarda relação direta entre benefícios e contribuições, ficando ao sabor das flutuações econômicas e das mudanças demográficas”. Em um regime de repartição, o crescimento econômico é relevante, haja vista implicar em aumento de ofertas de emprego e, consequentemente, a arrecadação de contribuições.

A previdência brasileira comporta dois regimes básicos, que são o Regime Geral de Previdência Social (RGPS) e os Regimes Próprios de Previdência de Servidores Públicos (RPPS), este último para servidores ocupantes de cargos efetivos (incluídos os efetivos) e os militares. Paralelamente aos regimes básicos existe o chamado regime complementar.

O regime complementar ao Regime Geral é privado, enquanto o complementar ao Regime Próprio é público, sendo em ambas as hipóteses o ingresso voluntário, tendo por objetivo ampliar os rendimentos na ocasião da aposentadoria. Os regimes básicos, 
especialmente o Regime Geral, não visam manter o padrão de vida do segurado, mas tão somente o necessário para o sustento do segurado e seus dependentes.

A natureza jurídica da Previdência Social é institucional ou estatutária, pois o Estado, por meio de lei, cria a figura da vinculação automática ao sistema previdenciário, independente da vontade do beneficiário, motivo pelo qual o seguro social é vinculado a ramo público ou social do Direito (Direito Previdenciário), em contrapartida ao seguro tradicional, que é vinculado a ramo privado (Direito Civil).

O sistema previdenciário brasileiro deveria ser autossustentável, ou seja, deveria ser financiado a partir das contribuições de seus participantes, evitando-se uma dependência indevida de recursos estatais, o que poderia comprometer o sistema protetivo.

Infelizmente, a realidade do sistema brasileiro é diferente do que prevê a teoria, que não foi responsável na administração das reservas, e, frequentemente, concedia benefícios sem a previsão de custeio específico, olvidando-se que a contributividade é característica básica do sistema previdenciário.

\section{A CONTRARREFORMA DO ESTADO BRASILEIRO}

A corrente neoliberal teve peculiar capacidade de modificar a essência do que é público sem necessariamente alterar sua aparência quando o fez ao mesclar algo que se tem a noção de ser coletivo, de acesso amplo (público) com algo que e restrito, particular (privado). Fazendo-o dentro de um contexto social oficialmente Democrático de Direito, onde, em tese, "todo o poder emana do povo", e no sentido literal também (demos = povo; cracia = poder).

Este processo se intensificou na década de 70 delimitado pelas prerrogativas acordadas pelo Consenso de Washington que defendia: a estabilização da economia através de uma inflação controlada, o ajuste fiscal, o Estado deveria ser mínimo ${ }^{4}$, privatizações, abertura comercial com alíquotas reduzidas de importação e o fim das restrições ao capital estrangeiro (BASTOS, 2003).

\footnotetext{
${ }^{3}$ Constituição Federal de 1988, Art $1^{\circ}$, Parágrafo único.

${ }^{4}$ Percebe-se aqui o que afirma Bastos (2003): "O velho liberalismo retornou, sob o disfarce de uma concepção moderna, para enfrentar os problemas econômicos do mundo capitalista e a crise dos países do leste europeu. $O$ cerne dessa concepção é o combate às ideias keynesianas de intervenção do estado na economia e ao estado do Bem-Estar Social, um retorno às ideias de Adam Smith, defendendo a "mão invisivel do Estado" como elemento essencial para regular as ações econômicas e sociais. (p.13-14)
} 


\subsection{Contexto neoliberal da Contrarreforma}

O neoliberalismo, diferente da corrente liberal, buscou ir além de simplesmente lutar pela exclusão do Estado na economia, e desenvolveu uma forma de penetrar nele de acordo com seus interesses. A intenção era segundo Bresser Pereira (responsável pela equipe de elaboração do Plano Diretor da Reforma), encontrar uma forma de recuperar do Estado sua governabilidade (legitimidade) e sua governance, isto é, sua capacidade de governo tanto financeiro quanto administrativo (BEHRING, 2008, p.173).

O Estado teria, pois, um papel coordenador suplementar onde deveria ser eficiente no que tange sua atuação social sem, contudo, incorrer no erro de ser novamente economicamente populista. Este deveria deixar de atuar diretamente na prestação de serviços e passar a ser provedor ou regulador dos serviços que seriam ou transferidos para o setor privado uma vez que poderiam ser controlados pelo mercado e/ou descentralizados para o setor público não-estatal.

Nesse contexto criou-se o Plano Diretor da Reforma do Aparelho do Estado (PDRAE). Elaborado pelo Ministério da Administração Federal e Reforma do Estado chefiado por Luis Carlos Bresser Pereira, o PDRAE traz em sua apresentação, feita por Fernando Henrique Cardoso (Presidente do país na época), a afirmação de que a crise que o país havia sofrido tratava-se também de uma crise do Estado que havia se desviado de suas funções para atuar também no setor produtivo, o que teria contribuído para "gradual deterioração dos serviços públicos" (BRASIL, 2005, p.6) diante do fato de que este não consegue ser eficiente diante das demandas que lhe são dirigidas.

O Brasil estava em crise desde nos anos 70, intensificada nos anos 80. A partir dos anos 90 buscou-se uma forma de reagir à crise através de uma reforma do aparelho (estrutura organizacional) do Estado que seria feito sob múltiplos aspectos redefinindo, portanto, o real papel do Estado que ficava isento da responsabilidade de promover o desenvolvimento socioeconômico do Brasil concernente a produção de bens e serviços.

Tornava-se dessa forma inadiável algumas ações como: (i) fazer um ajuste fiscal que fosse duradouro, (ii) orientar para o mercado as reformas econômicas juntamente com uma política tanto industrial quanto tecnológica capaz de concorrer interna e internacionalmente, (iii) reformar a previdência social e os instrumentos voltados para a política social como forma de obter uma maior abrangência e promover melhor qualidade para os serviços sociais 
e por fim (iv), a reforma da máquina estatal como forma de desenvolver de forma eficiente suas políticas públicas.

Houve uma necessidade de enquadrar-se à dinâmica do capitalismo contemporâneo o que influenciou no desmonte estatal. Tal sistema gerou uma reação em cadeia de devastação ${ }^{5}$, em espacial das instituições sociais. Não se tratou de destruição, na verdade houve um sucateamento do público. As instituições foram devastadas de forma concreta mantendo-se formalmente apenas. A devastação foi, portanto, uma forma sutil encontrada de redemocratizar. (PRAGA, p.21).

\subsection{Privatização do público}

A privatização do público funciona como um reforço à ilusão de que o Estado é facultativo ou mesmo desnecessário. Isso é justificado por diversos fatores como: i) a própria falência do Estado, através de sua dívida interna ou até mesmo diante de suas crises internas que atraiam com maior intensidadea atenção sobre as suas despesas (OLIVEIRA, p.18).

A prática da privatização é uma das características fundamentais da política neoliberal que ganhou na década de 70 com o Consenso de Washington. Defendia-se que ao afastar o Estado da economia e dos serviços públicos isso criaria novas oportunidades para os grupos privados asem contar as receitas extras que seriam geradas com a venda das empresas estatais e o a concessão dos serviços públicos. O Estado também ganharia com isso, pois com o valor recebido poderia sanar suas dividas, reduzi-las ou repassar para áreas que "julgasse prioritárias" (BASTOS, 2003, P.11-12), que no caso brasileiro foram: saúde, educação, justiça, segurança, ciência e tecnologia.

Na década de 1980, se tinha ainda uma fase de reprivatizações das empresas que, havia em algum momento, por motivos de insolvências financeiras, sido estatizadas. Aqui o objetivo ainda não era de se criar um programade privatizações em larga escala, uma vez que não era o foco gerar receitas para o tesouro ainda que isto tivesse ocorrido ${ }^{6}$ mas sim evitar ou reduzir as chances de ampliar ainda mais a presença do Estado no setor de produção. (LACERDA et al, 2005, p. 212)

\footnotetext{
${ }^{5}$ La 'devastacion de la democracia no significa su destruccion completa sino El despojo de su forma política.... La democracia termina así convertida em La forma política más apropriada AL desarrolo capitalista, y em La condición necesaria Del mejor funcionamiento del mercado. la 'devastacion' de La democracia es a parte de La devastacion Del Estado y de La política por parte Del mercado. (PRAGA, p.23)

${ }^{6}$ Segundo Lacerda et al (2005, p.212) nesse momento foram privatizadas 38 empresas, o que gerou, para os cofres públicos, uma receita de US\$ 780 milhões.
} 
Já na década seguinte (1990) o Brasil apresentou, nesse processo, algumas onde a principal delas era o que na verdade deveria (ou poderia) ser de fato privatizado ou não. Nesse instante, as privatizações contavam com um Plano de Desestatização (PND) onde nesse momento mais do que empresas, "o Governo repassava para o setor privado os custos da necessária modernização do país” (Ibidem, p. 229).

Tudo isso em nome de uma reforma do Estado, pois este teria "um papel coordenador suplementar" (BEHRING, 2008, p.173) e para que se resolvesse os problemas de insolvência financeira deste, excesso de regulação e rigidez e ineficiência do serviço público. Os defensores da privatização defendiam a crença de que o mercado seria bem mais eficiente que o setor público por estar inserido em um meio competitivo e isento de burocracia (DWECK, 2000, p.156).

Tratava-se de um Estado social-liberal, segundo Bresser Pereira apud Behring (2008, p.173) caracterizava-se como social porque focava em promover a defesa e implementar os direitos sociais ao passo que também era liberal não por que desejava “atingir o Estado mínimo, mas reconstruir um Estado que mantem suas responsabilidades na área social, acreditando no mercado, do qual contrata a realização de serviços, inclusive na própria área social” (BEHRING, 2008, p.172).

Entretanto o processo de retirar o Estado da esfera pública por meio das privatizações encontra resistências devidas, de forma contraditória, não corresponder a uma publicização do que é privado (OLIVEIRA, 2010, p.18), e isto para o Estado seria, segundo Francisco de Oliveira "sua dissolução, a apropriação privada dos conteúdos do público e sua redução de novo, a interesses privados" (Ibid, p.12). Funcionaria, segundo o autor (p.25) como uma forma de retrocesso a uma condição de mercadoria, que é, ao fim e a cabo, o principal objetivo neoliberal.

O fato irrefutável é como, de forma muito concisa e clara afirma Netto $(2007$, p.), a própria iniciativa de reforma do Estado foi proposta (para não dizer, imposta) pelo capital que conseguiu retirar do controle público não apenas empresas e serviços mas conseguiu que o próprio Estado entregasse "de bandeja" aos capitalistas a chance de explorar, privada e lucrativamente, os maiores complexos industriais existentes que perpassavam desde aos setores da siderurgia, indústria naval, automotiva e petroquímica até aos serviços considerado de especial importância tais como: distribuição de energia, telecomunicações, saneamento básico, bancos e seguros. 


\section{CONSIDERAÇÕES FINAIS}

O Brasil construiu sistema semelhante aos dos outros países, tendo a Constituição Federal de 1988 estabelecido um Estado de Bem-Estar Social em nosso território, transformando a proteção social brasileira em prioridade para o Estado.

Sabe-se que o Estado do Bem-Estar Social surgiu como um contraponto necessário ao crescimento do comunismo, pela conscientização dos dirigentes mundiais pela importância da proteção social. Nos últimos anos não tem como se ignorar o forte e significativo poder que a burguesia tem de retirar o Estado da economia através da grande transferência do patrimônio público para o setor privado.

A reforma do Estado brasileiro adquiriu centralidade crescente como resposta à crise, avançando como um projeto de modernização, incorporando nas suas proposições a privatização e redução do espaço público.

Entretanto, conclui-se que, a reforma do Estado apontada pelos movimentos populares, reconhecida na luta pelos direitos sociais consagrada no texto constitucional de 1988, no alargamento e democratização da esfera estatal e pública, deu lugar a uma contrarreforma sustentada em cortes orçamentários nas políticas de reprodução dos trabalhadores, marcadas pela ênfase à acumulação privada e à orientação para o mercado.

A reforma de Estado efetuada expressa a redefinição do papel regulador numa direção conservadora, atrelada às mudanças nas relações internacionais, a ser compreendida a partir da crise global do capitalismo e do protagonismo das agências financeiras internacionais

A justificativa de que a privatização é recomendada como forma de facilitar e amenizar as responsabilidades estatais faz com que, de outro lado, o cidadão ganhe uma nova face, de usuário detentor de direito a um consumidor restrito à condição de usar o que e quanto se pode pagar.

O grande desafio, ou melhor, obstáculo, é que não se pode combinar uma atuação genuinamente democrática (útil na garantia de direitos e de amplo acesso a estes) com o contexto neoliberal e comercial regido pelo favorecimento do crescimento e expansão do próprio sistema capitalista.

O cenário neoliberal, a passos não muito longos, porém, sutis vem encontrando brechas e fechando portas a muitos daqueles que poderiam entrar por direito e não por posse.

\section{REFERÊNCIAS}


BASTOS, F.M. Neoliberalismo, Projeto Neoliberal e Privatização do Brasil in

Neoliberalismo a recente política de privatização no Brasil: o caso da malha Nordeste da Rede Ferroviária Federal S.A -RFFSA. Dissertação (Mestrado em Engenharia de Transportes). UFC, Fortaleza, 2003. $167 \mathrm{f}$.

CASTEL, R. As metamorfoses da questão social: uma crônica do salário (trad. Iraci D. Poleti). 8. Ed. Petrópolis, RJ: Vozes, 2009.

CERQUEIRA FILHO, Gildásio. A questão social no Brasil. São Paulo: Saraiva, 1982.

DWECK, R.H. O MOVIMENTO DE PRIVATIZAÇÃO DOS ANOS OITENTA: REAIS MOTIVOS. Nova Economia| Belo Horizonte | v. $10 \mid$ n. 2 | dez. 2000

FURTADO, Celso. Formação econômica do Brasil. 10 ed. São Paulo: Editora Nacional, 1970.

IAMAMOTO, M. V. A questão social no capitalismo. Revista Temporalis - Associação Brasileira de Ensino e Pesquisa em Serviço Social. Ano 2. No 3 (jan/jul.2001). Brasília: ABEPSS, Grafline, 2001.

LACERDA, A.C.de; BOCCHI, J.I; REGO, J.M.; BORGES, M.A; MARQUES, R.M. Economia Brasileira - $2^{a}$ Ed. São Paulo: Saraiva, 2005.

MARX, Karl. O capital: crítica da economia política, Livro primeiro: o processo de produção do capital, Vol. I. Rio de Janeiro: Civilização Brasileira, 2013.

MENEGUETTI, Gustavo. A questão social no Capitalismo dependente. In:

https://ojs.franca.unesp.br/index.php/SSR/article/View/7. Acesso em 20 out 2017.

NAJBERG, Sheila; IKEDA, Marcelo. A economia brasileira nos anos 90: Previdência n Brasil - desafios e limites. 1999. Disponível em: www.bndes.gov.br . Acesso em: 20 de julho de 2012.

NETTO, J.P. Economia Política: uma introdução crítica. $3^{\text {a }}$ Ed- São Paulo: Cortez, 2007.

OLIVEIRA, F de. Privatização do público, destituição da fala e anulação da política: o totalitarismo neoliberal in Capitalismo, Estado e Desigualdade: Impactos na Política Educacional. Programa de Formação da APP-Sindicato / UFPR. Caderno II - 2010. Disponível em:

<http://www.appsindicato.org.br/adm/multimidia/coletivos/caminhoarquivo/64.pdf >

PRAGA, José Sanchez. Devastación de democracia em la sociedade de mercado. EquadorQuito: CAAP, 2011.

PRADO JÚNIOR, Caio. Formação do Brasil contemporâneo. 16 ed. São Paulo: Brasiliense, 1979.

REZENDE, Fernando. Finanças públicas. 2ed. São Paulo: Atlas, 2001. 
ROSAVAlLON, P. A. A nova questão social (trad. Sérgio Bath). Brasília: Instituto Teotônio Vilela, 1998.

TELLES, V. Questão social: afinal do que se trata? In: São Paulo em Perspectiva. Vol. 10 (4). SEADE: 1996.

YAZBEK, M. C. Pobreza e Exclusão Social: expressões da questão social no Brasil. Revista Temporalis - Associação Brasileira de Ensino e Pesquisa em Serviço Social. Ano 2. № 3 (jan/jul.2001). Brasília: ABEPSS, Grafline, 2001. 